\title{
Luta pelas lutas como prática pedagógica crítica na educação física escolar: sem rounds
}

Uirá de Siqueira Farias ${ }^{1}$, Daniel Teixeira Maldonado ${ }^{2}$, Valdilene Aline Nogueira ${ }^{3}$, Graciele Massoli Rodrigues $^{4}$

\section{Resumo}

Essa experiência tematiza as "lutas" com 29 crianças do $4^{\circ}$ ano do ensino fundamental, que aconteceu no último trimestre letivo de 2017, em uma escola pública da rede municipal de Santo André-SP. A "escrita de si" foi utilizada como possibilidade metodológica, ultrapassando a política acadêmica que se pauta no conhecimento objetivo e disciplinar, dando espaço e abertura para uma forma peculiar de ler e interpretar a narrativa de um relato de experiência efetivada por um docente de 33 anos que ministra aulas de Educação Física Escolar. O projeto educativo teve como objetivos ampliar os conhecimentos das crianças alargando a ideia que elas tinham das lutas e, aprofundar, de forma crítica, os aspectos que permeiam o universo do tema. Foi possível perceber com essa prática pedagógica um aprofundamento sobre o tema lutas, além do diálogo e reflexão crítica acerca da cultura corporal. Essa percepção se torna latente pelo desenrolar das atividades propostas de pesquisa pelo educador e estudantes, pelos debates e falas dos educandos e educandas e pelas avaliações realizadas pelas crianças durante o projeto educativo. Ressaltamos a necessidade de mais estudos que apresentem experiências pedagógicas sejam divulgados em periódicos da Educação para ampliação dos debates.

\section{Palavras-chave}

Educação Física Escolar. Práticas pedagógicas. Lutas.

\footnotetext{
${ }^{1}$ Doutorando em Educação Física na Universidade São Judas Tadeu, Santo André, São Paulo, Brasil; professor da rede municipal de Santo André, São Paulo, Brasil. E-mail: uirasiqueira@yahoo.com.br.

2 Doutor em Educação Física pela Universidade São Judas Tadeu, Santo André, São Paulo, Brasil, com estágio pós-doutoral na Universidade de São Paulo, Brasil; professor do Instituto Federal de Educação, Ciência e Tecnologia de São Paulo, Brasil. E-mail: danieltmaldonado@yahoo.com.br.

${ }^{3}$ Doutoranda em Educação Física na Universidade São Judas Tadeu, Santo André, São Paulo, Brasil; professora da Universidade de Guarulhos, São Paulo, Brasil; professora da rede municipal de São Paulo, São Paulo, Brasil. E-mail: valdilenenogueira@yahoo.com.br.

${ }^{4}$ Doutora em Educação Física pela Universidade Estadual de Campinas, São Paulo Brasil; professora adjunta da Universidade São Judas, Santo André, São Paulo, Brasil. E-mail: masgra@ @erra.com.br.
} 
Struggles for fights as critical pedagogical practice in school physical education: no rounds

Uirá de Siqueira Farias ${ }^{5}$, Daniel Teixeira Maldonado ${ }^{6}$, Valdilene Aline Nogueira ${ }^{7}$, Graciele Massoli Rodrigues $^{8}$

\begin{abstract}
This experience focuses on "fights", with 29 children from the 4th year of elementary school, in the last academic quarter of 2017, in a public school in the municipal network of Santo André/SP. The "writing of the self" was used as a methodological possibility, going beyond the academic policy that is guided by objective and disciplinary knowledge, giving space and opening to a peculiar way of reading and interpreting the narrative of an experience report carried out by a 33 years-old teacher who teaches Physical Education. The educational project aimed to expand the knowledge of the children by broadening the idea that they had of fights and, to critically deepen the aspects that permeate the universe of this theme. It was possible to perceive with this pedagogical practice a deepening on the theme of fights, in addition to dialogue and critical reflection on the body culture. This perception becomes latent due to the development of the proposed research activities by the educator and students, by the debates and speeches of the students and by the evaluations carried out by the children during the educational project. We emphasize the need for more studies that bring pedagogical experiences to be published in Education journals to expand the debates.
\end{abstract}

\title{
Keywords
}

School Physical Education. Pedagogical practices. Fights.

\footnotetext{
${ }^{5}$ PhD student in Physical Education, São Judas Tadeu University, Santo André, São Paulo, Brazil; Physical Education teacher at Santo André municipal network, São Paulo, Brazil. E-mail: uirasiqueira@yahoo.com.br.

${ }^{6} \mathrm{PhD}$ in Physical Education, São Judas Tadeu University, Santo André, State of São Paulo, Brazil, with postdoctoral stage at the University of São Paulo, Brazil; professor at the Federal Institute of Education, Science and Technology of São Paulo, Brazil. E-mail: danieltmaldonado@yahoo.com.br.

${ }^{7}$ PhD student in Physical Education at São Judas Tadeu University, Santo André, São Paulo, Brazil; professor at the University of Guarulhos, São Paulo, Brazil; Physical Education teacher at the municipal system of São Paulo, São Paulo, Brazil. E-mail: valdilenenogueira@yahoo.com.br.

${ }^{8} \mathrm{PhD}$ in Physical Education, State University of Campinas, São Paulo Brazil; adjunct professor at São Judas University, Santo André, São Paulo, Brazil. E-mail: masgra@terra.com.br.
} 


\section{Introdução}

O diagnóstico sobre a produção científica da Educação Física (EF) nos provocou uma grande reflexão: será que as práticas pedagógicas em Educação Física Escolar (EFE) efetivadas no "chão da escola" são, de fato, algo que os/as acadêmicos/as responsáveis pelas avaliações dos periódicos da Educação Física consideram relevante? Pela nossa experiência como professores/as que lecionam nas escolas e tentamos compartilhar, insistentemente, essas experiências pedagógicas em periódicos científicos da $\mathrm{EF}$, a resposta é não. Indo ao encontro desse nosso sentimento, o professor Valter Bracht (2017), ao prefaciar uma recente publicação que revela relatos de experiências de professores/as que vivem a realidade escolar, aponta que:

Isso se reveste de suma importância, particularmente porque contraria e corrige uma tendência presente na produção do conhecimento no âmbito dos programas de pós-graduação de Educação Física stricto sensu. Como venho argumentando, quanto mais próximo da CAPES mais longe da Escola fica a produção do conhecimento nesses programas. (BRACHT, 2017, p. 11).

Podemos inferir que pesquisas realizadas por docentes que vivem a realidade escolar não seguem uma lógica idêntica a das pesquisas acadêmicas, já que, na escola, os/as professores/as seguem uma tendência integrada e geral ligada à situação da prática que possui respostas mais imediatas diante das imprevisibilidades do fazer pedagógico. O/A professor/apesquisador/a, como aponta Alarcão (2001), seguem uma lógica simples em seu desenho, possuem um ritmo expressado pela rotina de ser educador/a, porém com profundidade de quem conhece de fato aquele contexto como ninguém.

As reflexões de Paulo Freire $(1996 ; 2014 ; 2017)$ nos ensinam que os preceitos educacionais precisam ser estreitamente ligados à busca da criticidade, da conscientização, do diálogo e, da construção de conhecimentos com sentidos e significados para educadores/as e educandos/as que caminham, em comunhão, para o aprofundamento dos temas.

A educação que promove criticidade enfrenta dificuldades de se efetivar no meio escolar e ainda anda em passos lentos nas escolas brasileiras (GIROUX, 1997). Alinhando-se a esse fato, a formação inicial em EF, assim como outras licenciaturas, apresentam-se descontextualizados da realidade das escolas, sem inserção no lócus escolar. Vê-se desconsideração acerca das relações entre saberes e práticas, e a ênfase na técnica apresentase proeminente. Ora a formação deveria capacitar para as diferentes formas de conhecer, de 
pensar e de fazer, colocando o/a aprendiz à prova diante de situações vivas, construídas no diálogo com as disciplinas, no estágio ou na pesquisa (ALVES; CARVALHO; DIAS, 2011).

$\mathrm{Na}$ perspectiva freiriana, é necessário que, nesse processo de modificar e criar um ambiente que favoreça a reflexão crítica, os/as educadores/as fiquem atentos/as para não se tornarem reféns de materiais didáticos muitas vezes vindos de instâncias governamentais que querem controlar a sua ação pedagógica, sequestrando a autonomia desses profissionais (FRANÇOSO; NEIRA (2014). Os autores colocam que os/as docentes, enquanto autores/as de suas práticas pedagógicas, jamais devem sucumbir aos dispositivos que tentam romper com seu poder de decisão diante da realidade escolar.

A autonomia docente é o ponto chave que pode modificar as práticas pedagógicas, sem esquecer os fatores sociopolíticos e culturais que, muitas vezes, dificultam as ações didáticas dos/das docentes de EF, já que eles/as ministram suas aulas faltando materiais, em espaços inadequados, recebendo um baixo salário e com uma formação continuada insuficiente (MALDONADO; SILVA, 2016).

Bracht et al. (2002) destacam que a década de 1980 foi um marco para o debate referente à formação crítica do professor de EF. As discussões realizadas na área se fortaleceram quando as Ciências Sociais e Humanas passaram a fazer parte da formação desse profissional, fortalecendo, inclusive, as análises sobre a função social da educação brasileira. Presenciava-se um sistema conservador que favorecia a reprodução dos modelos tradicionais baseados em mecanismos controladores de cunho ideológicos e excludentes, fortalecendo o status quo social.

Esses mesmos autores reforçam que o movimento iniciado em 1980 buscava alternativas para contribuir com a renovação da prática pedagógica nas aulas de EFE, a partir de pedagogias progressistas que tentavam levar a educação na direção de uma perspectiva igualitária e justa, ou seja, de transformação social (BRACHT et al., 2002).

As pedagogias críticas tinham o interesse de promover mudanças nas práticas pedagógicas de forma concreta, como a própria pedagogia de Paulo Freire, que se fortalecia ao relacionar a teoria com as ações didáticas dos/das docentes, conforme apontam Bracht et al. (2002).

Nesse cenário da EFE brasileira, em que ainda notamos a hegemonia dos esportes na escola e a desvalorização do conhecimento produzido pelos/pelas docentes que estão imersos no cotidiano escolar, estamos tentando tornar esse componente curricular cada vez mais reconhecido. Fazemos parte de um movimento, ainda tímido, que vem apostando na 
construção de novos significados para a disciplina na escola, possibilitando a criação de outra cultura para a EFE (RODRIGUES; BRACHT, 2010).

Assim, permeados/as por essas ideias, apresentamos uma prática pedagógica da EFE que tenta fugir das armadilhas impostas por políticas educacionais neoliberais que pouco estimulam os/as estudantes a refletir sobre o mundo, tampouco sobre as manifestações da cultura corporal durante as aulas do componente curricular.

Este relato de experiência pedagógica se apresenta com o intuito de dialogar com outros/as agentes da educação, utilizando a conscientização para munir as crianças de conhecimentos, que favoreçam a visão crítica da realidade, utilizando ainda a práxis dos/das docentes como essencial para reflexão sobre o mundo, pois somente o ser humano é capaz de atuar conscientemente sobre a realidade (FREIRE, 1979).

É com essa perspectiva que o presente trabalho relata a tematização das "lutas", com 29 crianças do $4^{\circ}$ ano do ensino fundamental, no último trimestre letivo de 2017 , em uma escola pública da rede municipal de Santo André/SP. Os objetivos que traçamos ao iniciar esse projeto educativo com os/as estudantes foram: ampliar os conhecimentos das crianças alargando a ideia que elas tinham das lutas; e, aprofundar, de forma crítica, os aspectos que permeiam o universo do tema, como o mercado que se criou em torno dessa prática corporal.

\section{Método}

Tomando o trabalho de Alves, Carvalho e Dias (2011) como referência, utilizaremos a "escrita de si" como possibilidade metodológica, ultrapassando a política acadêmica que se pauta no conhecimento objetivo e disciplinar, dando espaço e abertura para uma forma peculiar de ler e interpretar a narrativa de um relato de experiência efetivada por um docente de 33 anos que ministra aulas de EFE.

Nossa intenção é provocar reflexões nos/nas leitores/as interessados/as, com os quais, aqui, compartilhamos anseios e ações pedagógicas. Trazemos as nuances das inquietações de um professor que está em constante processo de reflexão sobre sua prática, pois "como metrificar um afeto, ou a intensidade do gosto, do prazer e do lúdico? A ciência pode até forjar respostas a essas perguntas, mas não sem antes abdicar daquilo que consiste nas sensibilidades" (ALVES; CARVALHO; DIAS, 2011, p. 242).

A "escrita de si" permite um exercício que movimenta o pensamento e estimula a sensibilidade de quem escreve, possibilitando que os conhecimentos constituídos em sua história de vida, suas marcas do tempo e das vivências se apresentem. 
Temos na "escrita de si", portanto, um exercício de reflexão que amplia a formação, pois extrapola a ordem do registro possível e alcança o registro das profundidades forjadas no encontro. E, sem a abertura a estas profundidades, o conhecimento não se implica no corpo e, portanto, não é colocado em movimento. (ALVES, CARVALHO; DIAS, 2011, p. 244).

Entendemos, assim, que colocar práticas pedagógicas à disposição da área pode vislumbrar um tipo de pesquisa que deve ser lida e interpretada como possibilidade de críticas que elevem, cada vez mais, o fazer pedagógico nas escolas. Divulgar os feitos dos/as docentes mostra que, em algumas escolas pelo Brasil, práticas comprometidas e transformadoras estão acontecendo, guiadas pela historicidade desses/as docentes. Abrilhantando essas considerações, Freire (1979) coloca que uma ideia só se faz ideia por meio da práxis e se efetiva pela esperança e pelo desejo utópico que cada professor/a carrega.

Diante de um cenário de desvalorização das pesquisas que tratam de análises qualitativas, o texto "História, memória e autobiografia na pesquisa educacional e na formação", de Catani et al. (2003), corrobora com nossas intenções, pois reconhece a ideia da autobiografia com potencialidade para análise em educação.

O reconhecimento das potencialidades educativas do trabalho com relatos de formação apoia-se na ideia de que a espécie de reflexão favorecida pela reconstituição da história individual de relações e experiências com o conhecimento, a escola, a leitura e a escrita permitem reinterpretações férteis de si próprio e de processos e práticas de ensinar. (CATANI et al., 2003, p. $19)$.

Os relatos autobiográficos ou histórias de vida, nos quais nos apoiamos para justificar esse trabalho, podem ser elementos para fornecer redimensionamentos de experiências na formação e nas trajetórias dos/as educadores/as, influenciando diretamente na forma de conduzir o ensino. Fortalecemos aqui a possibilidade de se trabalhar com a identidade do/da profissional, pois as questões de história de vida sempre estarão imersas em processos sociais e pessoais em uma dada realidade, que pode ser (re)significada a partir da reflexão (CATANI et al., 2003).

Ressaltamos que o professor que apresenta tal relato também é autor desse estudo, já que ele possui a prática de publicar suas ações pedagógicas em conjunto com outros/as pesquisadores/as. As informações aqui apresentadas são fruto de registros, tanto verbais quanto fotográficos, que fazem parte do arquivo pessoal do próprio educador e foram registradas como notas de campo. De posse desse material, o educador o apresentou a um pesquisador e uma pesquisadora, que visualizaram uma potencialidade nas informações. 
Assim, em novembro de 2019, conjuntamente, nos sentamos para definir os caminhos e a escrita do trabalho.

Todos os envolvidos na pesquisa assinaram o Termo de Consentimento Livre Esclarecido (TCLE), concordando em participar da produção, e o nome das crianças foram expressos de forma fictícia para garantir o anonimato.

\section{Resultados e Discussão}

$\mathrm{Na}$ busca por dar voz ao professor que escreve sobre si e, por consequência, sobre suas experiências pedagógicas, o relato que segue será compartilhado na primeira pessoa do singular.

\section{As lutas como prática da liberdade}

Duas grandes obras da EF me chamam a atenção quando penso em construir aulas numa perspectiva crítica: Metodologia do Ensino de Educação Física, de Soares et al. (1992) e Transformação didático-pedagógica do esporte, de Kunz (2014). Essas obras nos fazem repensar nossa prática, já que, a partir delas, tenho tentando fazer os meus alunos e minhas alunas olharem para além dos gestos motores, entendendo as práticas corporais como parte de um sistema sócio-histórico/cultural.

Confesso que essa tarefa tem sido muito, mas muito difícil para mim, e também para as crianças, pois quando eu vou para a sala de aula iniciar uma tematização ou discussão, eles e elas me perguntam constantemente, se "vamos para a quadra", mesmo estando comigo há alguns anos. Às vezes, tomado pelo desânimo, penso que meu trabalho não tem "dado resultado nenhum". Parece que somos movidos por resultados, constatações. É claro, isso tem origem na forma como fomos culturalmente apresentados à realidade social que valoriza a disputa e resultados, "até como comportamentos de sobrevivência", representado pela máxima do sistema nas avaliações dos estudantes.

Se recorrermos à teoria crítica, principalmente aos estudiosos da escola de Frankfurt, podemos nos apoiar na ampla discussão que esses autores travam contra uma ciência positivista, que caminha na contramão das particularidades sociais, históricas e culturais sufocando os fenômenos sociais e as relações de poder que aprisionam a sociedade, ou seja, os princípios que conduzem uma ciência social crítica, como o conhecimento construído historicamente, criticamente e dialeticamente (MARANHÃO; VILELA, 2017). 
Essas leituras me fizeram recordar meu percurso. Recém-formado, sempre busquei uma forma diferenciada de trabalhar, e acho que isso me motivou a buscar caminhos. Foi entre esses oito anos lecionando em escolas públicas de quatro municípios diferentes e buscando sempre estudar, dentro dos limites das amplas jornadas de trabalho, que me arrisquei a tematizar as lutas nas aulas de EFE.

No início, em 2010, eu aplicava uma atividade contada por um colega ali e outro aqui, e a utilizava nas aulas: aprendia e "usava" no outro dia com as crianças. Mas, insatisfeito com essa forma de trabalhar, percebi que era necessário me reinventar, me reconstruir, construir, sistematizar e trazer sentido para o papel docente e para a educação que estava ao meu alcance. Descobri que as lutas eram consideradas uma manifestação da cultura corporal que precisavam chegar aos/às educandos/as.

Passei a me perguntar se essa prática corporal estava sendo desenvolvida em outras unidades escolares durante as aulas de EFE. Ao revisar a literatura, tive uma grata surpresa e percebi que muitos/as docentes estavam organizando práticas pedagógicas relacionadas com essa manifestação da cultura corporal.

Verifiquei que Maldonado e Bocchini (2013) descreveram um projeto educativo, realizado com os/as estudantes do $5^{\circ}$ ano do ensino fundamental, em uma escola municipal de São Paulo, durante o ano de 2012. Nessa experiência, os/as discentes vivenciaram algumas lutas de forma adaptada (judô, sumo, esgrima, boxe e capoeira), inclusive com alguns convidados, professores formados nessas modalidades. Os autores assistiram produções cinematográficas, realizaram debates sobre o processo histórico dessas lutas, visitaram as principais regras e as capacidades físicas utilizadas nessas práticas corporais e refletiram sobre a diferença entre brigar e aprender uma modalidade de luta, além de analisar a violência que ocorre nas competições de Artes Marciais Mistas (MMA).

Lopes e Kerr (2015) também descreveram uma experiência pedagógica em que as lutas foram desenvolvidas com estudantes do $6^{\circ}$ ano do ensino fundamental de uma escola pública de São Paulo. A partir da realização de jogos, foram realizadas diversificadas lutas durante as aulas. Além disso, as crianças debateram e refletiram sobre o significado, o processo histórico, os princípios condicionais e as classificações das lutas.

Mais recentemente, Rocha, Oliveira e Machado (2017) descreveram a prática pedagógica de uma das autoras desse trabalho, realizada em uma escola de Educação Infantil de Vitória-ES. Em conjunto com as demais educadoras da escola, a docente organizou um projeto em que todas as crianças realizaram jogos e brincadeiras que envolviam os movimentos da capoeira. Vivenciaram uma roda de capoeira com todos os instrumentos 
musicais dessa prática corporal e refletiram sobre os conhecimentos de origem afro-brasileira que fazem parte dessa manifestação da cultura corporal.

Já Sousa (2017) relatou a sua prática pedagógica nas aulas de EF com educandos/as das séries iniciais do ensino fundamental do município de Santo André-SP. Nessas aulas, o autor organizou um projeto de ensino em que tematizou a esgrima com as crianças, durante o $2^{\circ}$ bimestre do ano de 2017. Ele realizou debates com os/as estudantes em círculos de cultura sobre a história dessa prática corporal, os materiais utilizados para vivenciar essa modalidade e se meninos e meninas poderiam realizar essa luta. Após essas reflexões, as crianças construíram uma espada com material reciclável e realizaram diversas atividades com alguns fundamentos da esgrima.

Silva Júnior (2017) desenvolveu uma experiência pedagógica em que tematizou o boxe, a capoeira e o jiu-jitsu com os/as estudantes das séries iniciais do ensino fundamental, de uma escola pública do município de Sorocaba-SP. Destaco que além dos/das discentes vivenciarem alguns movimentos dessas práticas corporais, os/as alunos/as, em conjunto com o docente, refletiram sobre questões de gênero, racismo e religião que atravessam constantemente essas manifestações da cultura corporal.

Do mesmo modo, Falconi e Farias (2017) colocaram em domínio público as experiências vivenciadas por um dos autores ao desenvolver as lutas na escola em que atuava. Nessa organização didática, os/as educandos/as vivenciaram diversos jogos de luta, realizaram uma oficina com professores convidados/as de judô, jiu-jitsu e capoeira e montaram um painel para a mostra cultural da escola sobre a história, técnicas, principais lutadores e filosofia do jiu-jitsu.

Ao analisar a literatura da área, foi possível perceber uma grande variedade de experiências educativas, muito semelhantes à que descrevi nesse relato de experiência, em que os/as docentes de EF tematizaram as lutas em suas aulas. Assim, animado com o que pesquisei, reuni-me com outros dois professores e construímos uma sistematização didaticamente planejada.

Como em qualquer realidade escolar, nem sempre as aulas que eu organizava sobre essa prática corporal se desenvolviam atendendo ao que se esperava. Aos poucos, fui percebendo que era necessário que as turmas alcançassem confiança nas relações construídas comigo e com seus pares para que os objetivos traçados e os temas escolhidos pudessem ser parte da EF.

Trabalhar o tema "lutas" em uma turma com diversas dificuldades de convivência ainda me instiga revisitar as reflexões, debates e vivências acerca dessa prática corporal nas 
aulas de EFE. Um dos motivos é a própria ideia de luta veiculada pela mídia de massa. Muitas vezes as crianças querem reproduzir aquilo que assistem.

E, nessas idas e vindas reflexivas, fui tentando constituir uma prática pedagógica, não só com as lutas, mas com outras tematizações, que favorecem as crianças a olharem para o espectro de possibilidades que um tema possui que, muitas vezes, está camuflado na sociedade. Olhar para minhas próprias práticas e refleti-las foi algo essencial para repensar minhas ações pedagógicas com intenção crítica. Ciente de que o caminho é longo, já é tempo de reacender a difícil criticidade, em mim e nos/as estudantes, a fim de transformar os processos sociais.

Foi no terceiro trimestre de 2017 que o tema lutas surgiu. Eu tinha a intenção de ampliar as discussões e as possibilidades de vivências corporais das crianças do $4^{\circ}$ ano do ensino fundamental I, de uma escola pública do município de Santo André-SP. Essas crianças, ao serem questionadas na primeira aula sobre o que era luta, responderam de imediato "briga", "violência" e "esporte". Ali, estava presente a simples e limitada leitura midiática.

A associação que elas fizeram com o esporte nos tocou. Emergiu como sinônimo de violência. Ao perceber tal confusão, confesso que fiquei muito surpreso e preocupado, pois minha ideia era trabalhar com as lutas na expectativa que tais distorções não existissem. Tenho procurado promover uma metodologia dialógica e participativa, em que de fato as crianças se sintam parte da construção das aulas. Fui surpreendido pela imprevisibilidade, ainda mais por ser uma turma que, embora estivesse comigo há três anos, nunca tínhamos estudado as lutas nas aulas de EFE.

As respostas das crianças me levaram diretamente à discussão feita por Adorno, citado por Benjamin et al. (1980) sobre a indústria cultural. Destaco a exploração feita pelo mercado dos eventos esportivos sob a febre atual do MMA. Levanto a exploração dos bens culturais em detrimento do consumo para as massas, nesse caso, a manifestação cultural das lutas. Se as lutas não eram elitizadas, agora são.

Com a aula diagnóstica, e na intenção de fazer com que as crianças se aprofundassem no tema, solicitei que cada uma realizasse uma pesquisa em casa sobre o que era luta. Percebendo que somente o aprofundamento das crianças não seria suficiente, busquei materiais de apoio para conduzir os próximos passos. Foi então que entrei em contato com o material didático do Ministério do Esporte, Lutas, Capoeira e Práticas Corporais de Aventura, organizado por González, Oliveira e Darido (2017). Pautei-me, assim, nesse referencial para estruturar algumas ações do planejamento. 
Com material em mãos, construí uma unidade didática sobre as características gerais das lutas, como: o enfretamento físico direto; as regras; a oposição entre os indivíduos; o objetivo centrado no corpo da outra pessoa; nas ações de caráter simultâneo; e na imprevisibilidade. Todos esses conteúdos foram discutidos ao longo do trimestre em diversas aulas.

Há algum tempo venho utilizando o caderno de registros com algumas turmas e o $4^{\circ}$ ano já vinha usando essa ferramenta como instrumento pedagógico. As crianças registram as aulas, suas curiosidades e trabalhos tratados na EFE. Tudo que acontece e que necessita ser registrado é feito nesse instrumento e a pesquisa sobre as lutas teve suas anotações lá.

Quando as crianças retornaram com as pesquisas, organizei uma discussão sobre seus achados. Cada criança poderia falar suas impressões após uma busca sobre a temática. Além disso, preparei uma atividade com imagens de pessoas brigando e outras realizando algum tipo de luta. Entreguei uma para cada criança e as orientei para discorrer de forma escrita quais imagens eram brigas e quais eram lutas.

Essa foi uma experiência enriquecedora, já que a grande maioria conseguiu distinguir as imagens. Após essas duas ações, perguntei se eles/as ainda consideravam as lutas como briga e violência, e obtive respostas animadoras: "professor, eu não sabia que as lutas não eram briga"; "agora eu percebo que as lutas possuem regras que diferenciam e muito elas das brigas". É claro que tive percepções instigantes, como o questionamento do aluno Vitor: "Mas professor, eu assisto as lutas e vejo que o lutador sangra, se machuca, até desmaia. Como isso não é violência"?

Nesses momentos, visito os reducionismos das minhas próprias respostas: as lutas no contexto esportivo possuem suas regras e todos que se submetem ao esporte estão de acordo. Pedi que os/as discentes se reunissem em grupos e tentassem trazer respostas ao questionamento do Vitor. Alguns grupos trouxeram a ideia de oposição: é sempre necessário em uma luta que se tenha alguém para opor forças, por esse motivo algumas modalidades tinham contatos físicos que chegavam a machucar e que isso fazia parte das regras. Complementando, apontaram a possibilidade de só se disputar modalidades como o braço de ferro, o cabo de guerra, ou lutas com equipamentos que pudessem ter proteção aos participantes.

Foi nessa brecha que iniciei a conversa sobre o que de fato iríamos praticar nas aulas sobre lutas. Levando em consideração o aprofundamento que já vínhamos fazendo sobre a oposição de força, as lutas de curta, média e longa distância e com contato direto, apresentei 
uma séria de lutas que fui aprendendo com colegas, alunos/as e inclusive professoras pedagogas ao longo da minha trajetória na área.

Figura 1 - Atividade sobre ossos

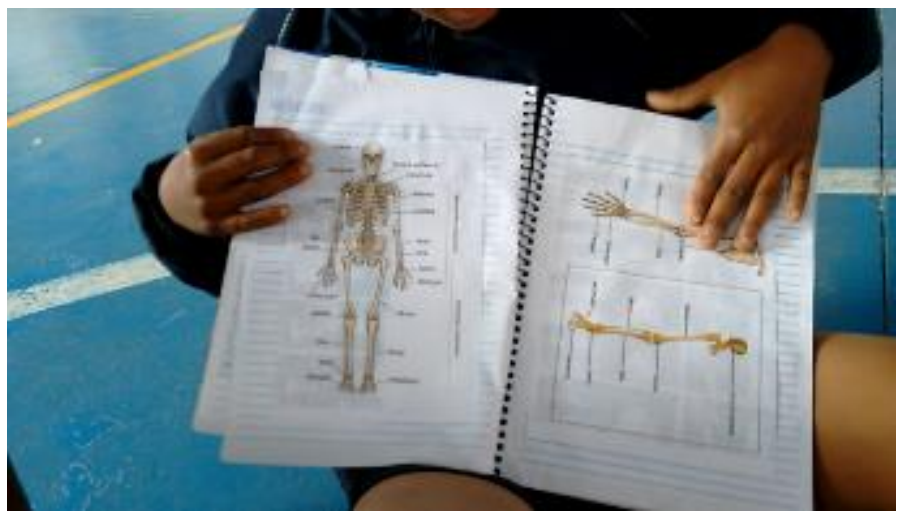

Fonte: Os autores (2020).

Como de costume, eu mostrei algumas atividades e também sugeri que as crianças recriassem ou até mesmo apresentassem outra atividade para enriquecer o planejamento. Os jogos utilizados foram: pega fita; esgrima de mão; escalpo; lutas dos polegares; luta das palmas; golpes nas bexigas; desviando dos pneus; cabo de guerra, cabo de guerra duplo; sumô em círculo; braço de ferro; luta do desequilíbrio na linha e no banco; luta numerada; luta do pregador; luta do galo; e luta medieval.

Alguns/Algumas alunos/as ficaram surpresos e outros desapontados quando perceberam que as atividades não se assemelhavam ao famoso MMA, inclusive me questionando se isso era luta.

Reuni todos/as em círculo e perguntei sobre as características que envolvem as lutas. Será que essas atividades possuem oposição de força, contato direto ou indireto? Ou seja, retomei os conceitos discutidos em aulas anteriores. Foi então que as crianças começaram a perceber que as nossas lutas possuem características que se diferenciam daquelas assistidas na TV. Percebi o quanto as questões midiáticas influenciam na forma como elas enxergam as lutas, e que mesmo tentando aprofundar o conhecimento de tal manifestação, a mídia ainda é coerciva nas leituras delas. Isso tem sido um desafio. É como se eu tivesse que recomeçar todos os dias.

Durante a aplicação dessa unidade, também notei que as crianças possuíam uma grande dificuldade em reconhecer partes do corpo, como a divisão dos membros superiores e inferiores. Essa situação aflorou necessidades e oportunidades que podem remodelar nosso 
planejamento e conduzir ajustes constantemente. Foi então que elaborei uma atividade para reconhecimento, inicialmente dos ossos e, posteriormente, da divisão dos membros. Essa atividade foi bem aceita pela turma. Algumas crianças declararam que as atividades que envolveram o reconhecimento das partes do corpo foram as mais marcantes e trouxeram muito aprendizado dentro da tematização das lutas. Ao questionar a turma sobre o que mais foi relevante nas discussões sobre as lutas, a aluna Mônica ressaltou: "Eu fiquei muito feliz em aprender os ossos que fazem parte do nosso corpo".

A ideia de aprofundar as questões das partes do corpo foi essencial para o desenvolvimento das lutas propostas na unidade, como, por exemplo, a esgrima de mão, na qual, em duplas, cada aluno/a teria que tocar uma parte preestabelecida e combinada para pontuar no jogo, ou seja, se as crianças combinarem que devem tocar no ombro, cada toque realizado com sucesso equivale a um ponto.

Figura 2 - Luta: Esgrima de mão

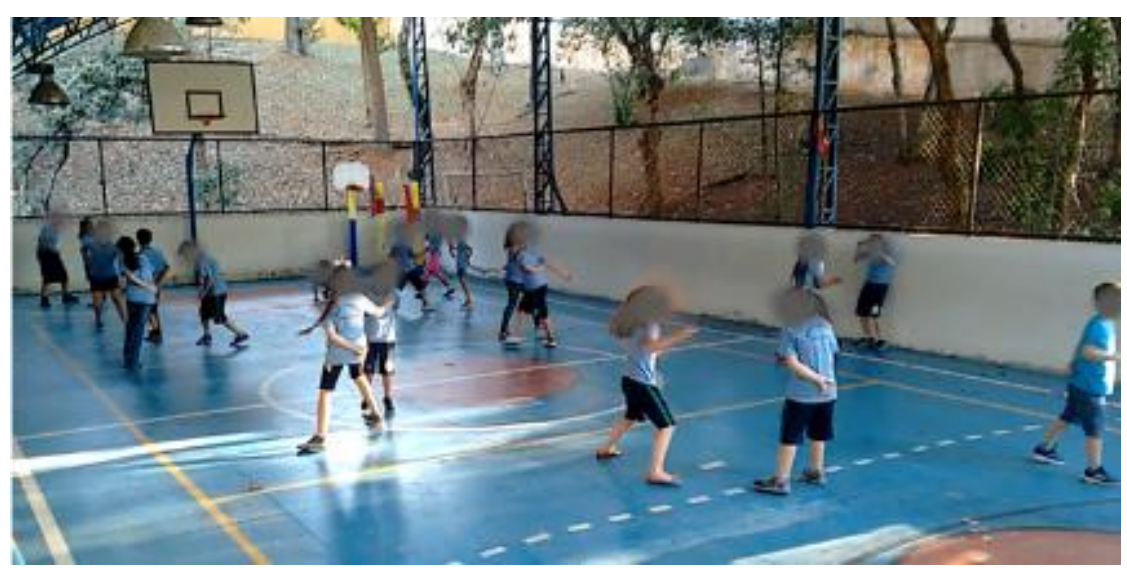

Fonte: Os autores (2020).

Mesmo com esses avanços ainda senti que as discussões não apresentavam olhares para além dos aspectos do fazer. Era necessário estimular as crianças a refletirem sobre as questões mercadológicas que, muitas vezes, controlam a opinião e a vontade pelo consumo delas. Foi aí que fiz a proposta de mais um exercício de análise.

Elas seguiram para casa com a tarefa de assistir um evento qualquer de luta e tentar trazer, para a aula seguinte, apontamentos que chamaram sua atenção. Pontuei na explicação que elas deveriam sensibilizar seus olhares para as coisas que, muitas vezes, nos passam desapercebidas. O retorno dessa atividade foi muito interessante, pois as meninas, em sua grande maioria, trouxeram questionamentos valiosos. Organizei a turma em círculo e abri para que as crianças colocassem seus achados. 
A aluna Marcia abriu as discussões falando: "Professor, como é possível um evento de luta, que parece uma jaula, reunir tantas pessoas? Eu acho que deixa parecendo uma luta de animais". O aluno Marcelo completou: "É para deixar um clima de guerra, e aí os lutadores não podem fugir, entrou tem que lutar!”. A aluna Silvia, acrescentou: “Gente, é obvio que tudo isso é para ganhar dinheiro, quem organiza e quem luta vai ganhar muito dinheiro, aí o ambiente tem que ser assim, tem que chamar a atenção para as pessoas irem assistir”.

Falas como essas começaram a aparecer, enriquecendo o debate sobre o tema. Surgiram desde questões de lucro para aqueles que organizam o evento, até quem são as pessoas mais vistas na plateia, sendo em sua grande maioria homens. Outro questionamento muito interessante foi sobre a questão das meninas que carregam a placa dos rounds, "elas precisam estar de biquíni?", perguntaram. Alguns meninos levantaram o fato de as pessoas estarem comprando muitos produtos do Ultimate Fighting Championship (UFC), mesmo sendo caros.

Figura 3 - Luta do galo

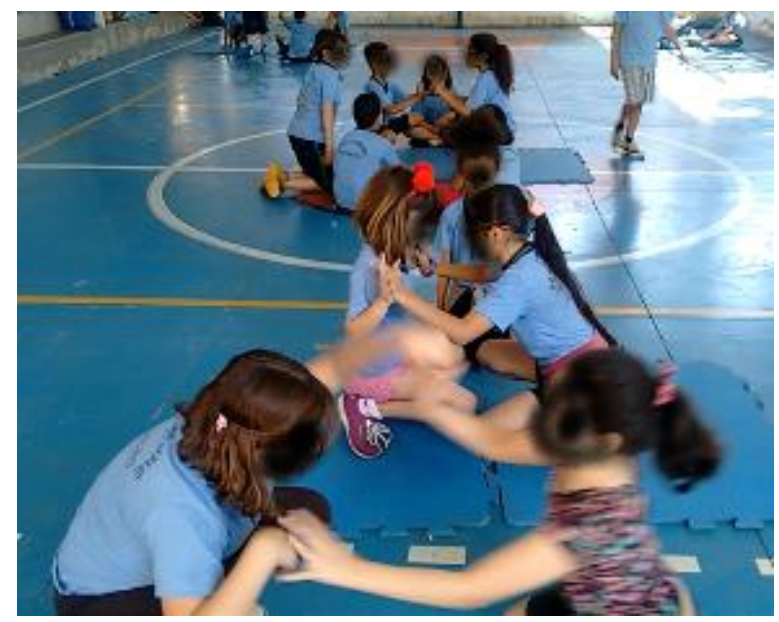

Fonte: Os autores (2020).

Após tudo isso, comecei a problematizar assuntos que eles/as necessitavam refletir: Será que a nossa luta escolar é a mesma que passa na TV? As pessoas necessitam mesmo comprar roupas que carregam uma marca? Se eu estiver usando uma roupa sem marca, eu não posso me sentir bem? Qual é a visão que os telespectadores do UFC têm das mulheres nesse esporte? Qualquer pessoa tem condições de ir assistir uma luta dessas?

Finalizei a aula, pedindo que as crianças pensassem na importância do conhecimento sobre qualquer esporte para saberem fazer boas interpretações, saberem ver o que é interessante e sempre fazer uma análise crítica das coisas, pois há ações e esportes que mais 
excluem do que possibilitam a participação das pessoas, e não nos permitem uma leitura e interpretação das relações de poder que permeiam nossas vidas.

Entre discussões e vivências sobre lutas, passamos três meses aprendendo juntos. As avaliações realizadas nessa unidade levaram em consideração as atividades vivenciadas, as tarefas de casa, o caderno de registros, uma avaliação e autoavaliação feitas no ambiente virtual.

\section{Considerações provisórias}

Reafirmo que inserir as crianças em uma cultura escolar que favoreça a criticidade não tem sido uma tarefa fácil. Lidar com os preceitos trazidos pelos/as autores/as da Pedagogia Crítica é um desafio para educadores/as que tentam exercer, no dia a dia da sala de aula, práticas que dialoguem com a construção de outro tipo de sociedade, menos feia e meio desigual (FREIRE, 2014).

Com o relato de experiência, aqui narrado, foi possível perceber aprofundamento do tema, diálogo e reflexão crítica acerca da cultura corporal. Essa percepção se torna latente pelo desenrolar das atividades propostas de pesquisa pelo educador e estudantes, pelos debates e falas dos/as educandos/as e por todas as avaliações realizadas pelas crianças durante o projeto educativo.

Trouxemos uma tentativa de se aproximar desse ideal e que, cientes dos possíveis tropeços pela essência própria de seu inacabamento, advoga pela ampliação dos conhecimentos sobre as lutas na EFE. Buscamos estabelecer relações que extrapolam o viés procedimental que tanto habita a escola. Ainda, em diálogo com Borges (2019), descrevemos as relações de poder existentes no cotidiano escolar para estruturar a prática pedagógica, além de destacar a nossa produção discursiva inspirada pelas teorias críticas de currículo.

Como toda vivência que se calça nas vestes da crítica, da autocrítica, na transformação e reconstrução da realidade, buscamos compartilhar um momento construído sobre a temática lutas. Entendemos que esse momento não foi ainda finalizado, mas aguçado pelas estruturas temporais que a escola impõe. Esperamos que, ao partilhar as experiências com nossos pares, sejamos capazes de acender a chama da escola como espaço de criação coletiva com aqueles que passaram pela experiência e com os que nela se inspirarão. 


\section{Referências}

ALARCÃO, I. Professor-investigador: que sentido? que formação? Cadernos de Formação de Professores, Aveiro, n. 1, p. 21-30, 2001. Disponível em:

http://www.educ.fc.ul.pt/docentes/jponte/sd/textos/alarcao01.pdf. Acesso em: 15 mar. 2020.

ALVES, F. S.; CARVALHO, Y. M.; DIAS, R. A "escrita de si” na formação em educação física. Movimento, Porto Alegre, v. 17, n. 2, p. 239-258, abr.-jun. 2011. Doi: 10.22456/19828918.20214.

BENJAMIN, W. et al. Textos escolhidos. São Paulo: Abril Cultural, 1980. (Coleção Os Pensadores).

BORGES, C. C. O. Governo, verdade, subjetividade: uma análise do currículo cultural da educação física. 2019. Tese (Doutorado em Educação) - Faculdade de Educação, Universidade de São Paulo, São Paulo, 2019. Doi: 10.11606/T.48.2019.tde-04112019165709.

BRACHT, V. et al. A educação física escolar como tema da produção do conhecimento nos periódicos da área no Brasil (1980-2010): parte I. Movimento, Porto Alegre, v. 17, n. 2, p. 11-34, 2011. Doi: 10.22456/1982-8918.19280.

BRACHT, V. et al. A prática pedagógica em educação física: a mudança a partir da pesquisaação. Revista Brasileira de Ciências do Esporte, Campinas, v. 23, n. 2, p. 9-29, 2002.

BRACHT, V. Prefácio. In: NOGUEIRA, V. A.; FARIAS, U. S.; MALDONADO, D. T. (org.). Práticas pedagógicas inovadoras nas aulas de educação física escolar: indícios de mudanças 2. Curitiba: CRV, 2017. p. 11.

CATANI, D. B. et al. Docência, memória e gênero: estudos sobre formação. 4. ed. São Paulo: Escrituras, 2003.

FALCONI, C. A.; FARIAS, U. S. "Its time" a luta na escola: uma perspectiva através dos jogos de oposição. In: FARIAS, U. S.; NOGUEIRA, V. A.; MALDONADO, D. T. Práticas pedagógicas inovadoras nas aulas de educação física escolar: indícios de mudanças. Curitiba: CRV, 2017. p. 101-114.

FRANÇOSO, S.; NEIRA, M. G. Contribuições do legado freireano para o currículo da educação física. Revista Brasileira de Ciências do Esporte, Florianópolis, v. 36, n. 2, p. 531-546, abr.-jun. 2014. Doi: 10.1590/S0101-32892014000200017.

FREIRE, P. Conscientização: teoria e prática da libertação: uma introdução ao pensamento de Paulo Freire. São Paulo: Cortez \& Moraes, 1979.

FREIRE, P. Pedagogia da autonomia: saberes necessários à prática docente. São Paulo: Paz e Terra, 1996.

FREIRE, P. Pedagogia do oprimido. 17. ed. Rio de Janeiro: Paz e Terra, 2017.

FREIRE, P. Pedagogia da esperança: um reencontro com a pedagogia do oprimido. São Paulo: Paz e Terra, 2014. 
GIROUX, H. A. Os professores como intelectuais: rumo a uma pedagogia crítica da aprendizagem. Porto Alegre: Artes Médicas, 1997.

GONZÁLEZ, F. J.; DARIDO, S. C.; OLIVEIRA, A. A. B (org.). Lutas, capoeira e práticas corporais de aventura. 2. ed. Brasília: Ministério do Esportes; Maringá: EDUEM, 2017.

KUNZ, E. Transformação didático-pedagógica do esporte. 8. ed. Ijuí: Editora da Unijuí, 2014.

LOPES, R G. B.; KERR, O. O ensino de lutas na educação física escolar: uma experiência no ensino fundamental. Motrivivência, Florianópolis, v. 27, n. 45, p. 262-279, 2015. Doi:

10.5007/2175-8042.2015v27n45p262.

MALDONADO, D. T.; BOCCHINI, D. As três dimensões do conteúdo na educação física: tematizando as lutas na escola pública. Conexões, Campinas, v. 11, n. 4, p. 195-211, 2013. Doi: 10.20396/conex.v11i4.8637599.

MARANHÃO, C. S.; VILELA, J. R. P. X. A imanência entre a teoria crítica e a pesquisa empírica: contribuição para os estudos organizacionais. O\&S, Salvador, v. 24, n. 82, p. 476490, jul.-set. 2017. Doi: 10.1590/1984-9240826

ROCHA, M. C.; OLIVEIRA, S. R. B.; MACHADO, T. S. Capoeira na educação infantil: brincando com os saberes da cultura afro-brasileira. In: NOGUEIRA, V. A.; FARIAS, U. S.; MALDONADO, D. T. Práticas pedagógicas inovadoras nas aulas de educação física escolar: indícios de mudanças 2. Curitiba: CRV, 2017. p. 49-62.

RODRIGUES, L. L.; BRACHT, V. As culturas da educação física. Revista Brasileira de Ciências do Esporte, Campinas, v. 32, n. 1, p. 93-107, set. 2010. Doi: 10.1590/S010132892010000400007.

SILVA JÚNIOR, W. S. Lutas diversificadas para a diversidade da educação física escolar. In: NEIRA, M. G. Educação física cultural: o currículo em ação. São Paulo: Labrador, 2017. p. 200-212.

SOARES, C. L. et al. Metodologia do ensino de educação física. São Paulo: Cortez, 1992.

SOUSA, C. A. Esporte de combate: a esgrima como prática pedagógica inovadora nas aulas de educação física escolar. In: FARIAS, U. S.; NOGUEIRA, V. A.; MALDONADO, D. T. Práticas pedagógicas inovadoras nas aulas de educação física escolar: indícios de mudanças 2. Curitiba: CRV, 2017. p. 115-128.

Submetido em 4 de abril de 2020.

Aprovado em 8 de maio de 2020. 